\title{
DELIBERATE DISPUTE AND THE CONSTRUCTION OF OPPOSITIONAL STANCE ${ }^{1}$
}

\author{
Karen L. Adams
}

\section{Introduction}

Participant displays of oppositional stances are anticipated features in the events discussed here, gang graffiti and televised political debates and political commentary shows. Failure to show a certain degree of verbal confrontation in these contexts would be noteworthy as these are typically contests with winners and losers not interactions with compromise. In the televised events, the goal is to convince viewers (some of whom are already convinced) that one's approach, ideology and style is more valid than another's. Achieving these goals can mean winning an election, encouraging others to pressure political leaders or creating more solidarity among the groups in question. And, while gang graffiti has many functions including creating social cohesion, (see Adams and Winter 1997), in dispute usage, superiority and its assertion are at stake, not mediated resolution. Despite differences in the participants and goals of these activities, these examples of deliberate dispute can be shown to share a large number of linguistic strategies. Such shared features can most appropriately be understood through applying indexicality theory to notions of co-construction and intertextuality thereby leading to a broader and deeper understanding of these approaches and the strategies in question.

These events or genres ${ }^{2}$ are distinct from related activities, and may have parallels in activities such as sporting events with opposing teams and in labor-management negotiations. All the participants in these activities belong to opposing groups, and the events themselves are designed to bring these groups into interactional struggle with each

${ }^{1}$ I would like to thank Dawn Bates, Elly van Gelderen, Tom Hudak and Marysia Johnson for their comments on this paper as well as two anonymous reviewers.

${ }^{2}$ Whether the events in question are more accurately referred to as speech events, genres of speaking or activity types (Levinson 1992) is a possible topic of discussion. I will alternate between the three as these events appear to be separate genre involved in activities that consist in large degree of speaking. Televised political debates have often been criticized as being a bad cross between an academic debate genre and an interview genre. While the nature of their format has shifted over the last few years partly in response to these criticisms, they are now a standard part of the political repertoire in the U.S.A. regardless of their hybrid nature and could easily be considered a separate genre. Gang graffiti also shares similarities with other graffity types such as interactive laternalia writing, but it is an antilanguage designed for restricted audiences and is not decodeable by all unlike much other graffiti including political graffiti. Lastly, political talk shows now even have their own parody in the United States in the form of a TV show called "Politically Incorrect" whose existence is dependent on an identifiable canonical event. 
other. They are part of a larger number of conflict activities that may be sustained. For example, Goodwin 1990 describes spontaneous arguments among children where mediation and compromise are rare; rather the disagreement is merely dropped for a time. According to Grimshaw 1990 such unresolved exchanges are probably more common than we think, and two recent volumes, Tannen (1998) and Briggs (1997a) have brought additional focus to conflict interactions since the innovative work found in Goodwin and Grimshaw.

Briggs (1997b: 456) notes analyses of conflicts are part of a "growing body of work that questions order and orderliness [as] inherent in speech," arguing that such events have been ignored as research data as have the examples of the prepared and public language analyzed here. He claims that the focus on everyday interactions seen as naturally occurring has pushed to the periphery of pragmatics an understanding of the events characterized here since two of them are prepared and public and one, gang graffiti, would never be considered naturally occurring conversational speech. ${ }^{3}$ Haviland (1997) extends Briggs (1997b) by noting that not only conversational analysis with its one-at-a-time turn-taking model, but also the emphasis on speech act theory and on the Gricean cooperative principle with its ensuing maxims have led to a research emphasis on analyzing orderly, cooperative speech.

Tannen (1998) addresses public and prepared events related to those discussed here claiming that many have become unnecessarily confrontational, i.e. 'agonistic.' While she sees agonism as increasing in the U.S.A. in a disruptive way and suggests models for other interactional styles, her discussion of these public agonistic moments are mostly from a rhetorical and social perspective. Little is presented to us about the linguistic strategies that participants use to co-construct these events.

As Brenneis (1988: 229) states "Language is not an epiphenomenal reflex of relations, indeed, it often creates and shapes those relations." These relations may be cordial or they may not be; both types require co-construction by speakers. ${ }^{4}$ Identity as an oppositional self is just as surely co-constructed linguistically as that of a cooperative self since oppositional stances cannot be created without the perception of a contrasting position/ideology and a person associated that position. Co-construction is necessary to understand the data in question since the opposition of one participant builds on the presentation of self of the other. The shared linguistic strategies for building opposition discussed below suggest a limiting effect on the freedom to co-construct identities in deliberate disputes.

Jacoby and Ochs (1995) note that many disciplines have brought understanding to the nature of co-construction including conversational analysis, soviet psychology, linguistic anthropology and Bakhtinian literary theory. However, in their discussion on coconstruction, their emphasis on conversational analysis and their failure to clarify how to integrate the different approaches leave us looking for a way of explaining the data described below. For example, they claim (1995: 177) that

${ }^{3}$ Blume 1985, for example, refers to graffiti as a kind of defective communication.

${ }^{4}$ I will use terms referring to spoken language throughout, though in the case of gang graffiti, these exchanges are written and designed to avoid co-presence with a hostile gang. (For further discussion of this issue, see Adams and Winter (1997 and forthcoming). 
"...language, discourse and their effects cannot be considered deterministically preordained by alleged 'inherent' properties of linguistic structures, by assumed constructs of individual competence and so-called shared knowledge, or by assigning participants to membership categories presumed to be relevant to the occasion."

Yet we will see that deliberate dispute exhibits recurring examples of participant assignment and strategies to create oppositional stance. They also note that "Bakhtin's ideas have informed current thinking about ways in which spoken and written texts from other times and places meld into the construction of ongoing texts," but do not try to bring the Bakhtinian and conversational analysis approaches together (Jacoby and Ochs 1995: 174). The theory of indexicality presented in Ochs 1990 and 1992 and developed from earlier work in pragmatics on indexicality and from sociolinguistics and anthropological linguistics work on social markers and indicators can be employed to explain the linguistic similarities found here regardless of the differing nature of the participants, topics disputed and consequences of dispute.

\section{Data}

Two of the data sources discussed here are drawn from televised events. One set is 57 political debates broadcast from 1984 to 1996 between candidates running for various offices in governing bodies in the United States. The offices range from President of the United States to local council seats. Both male and female candidates are represented as are third party candidates and candidates with different ethnic and regional backgrounds. ${ }^{5}$

The second televised event is the political commentary show, "To The Contrary," the first all-female political news/commentary show in the U.S. ${ }^{6}$ Produced by the Maryland Public Broadcasting System and broadcast around the country, two broadcasts from January 21 and 28, 1993 are discussed here. The show is advertised on its web site as "a discussion of issues from a variety of women's perspectives" ("To The Contrary" 1998). Its moderator, Bonnie Erbe, both comments and directs panelists representing various ethnic communities who are journalists and commentators from political think tanks on both the left and right of the political spectrum. The two commentary shows in question deconstruct of the notion of a unified women's voice in politics as well as the stereotype that women avoid confrontation.

The last deliberate dispute genre is gang graffiti collected in the Phoenix metropolitan area and overwhelmingly male in its authorship. The graffiti is written on a variety of surfaces, mostly cement block fences and sides of buildings, but it occurs on any surface which can be inscribe including sides of trucks, stop signs and picnic tables. Photos of the graffiti were collected between 1993-1995 and reported on in detail in Adams and

\footnotetext{
${ }^{5}$ These debates actually have a higher than usual proportion of female candidates, moderators and panelists as they were collected for a project that was designed to consider the construction and effect of gender in debate styles.

${ }^{6}$ Towards the end of its third year, 'To The Contrary' altered its format to include more male commentary probably in an effort to 'widen' its viewing audience.
} 
Winter 1997 and Adams and Winter (forthcoming). ${ }^{7}$

Each of these interactions is only part of a series of larger on-going dispute activities among the participants which occur in other venues and in other formats. While not reflecting the entire process of conflict, these are public exchanges that observers have access to, though in the case of graffiti, typically only after the event. In contexts outside of the deliberate dispute arenas, particularly in the media events, but in the case of gang graffiti also, the people involved may or may not systematically maintain the opposition demonstrated in these public exchanges.

\section{Shared strategies for constructing opposition}

\subsection{Specification of membership and ideological stance}

In her discussion on indexing gender Ochs argues (1992: 336-337) "...that the relationship of language and gender is constituted and mediated by the relation of language to stances, social acts, social activities, and other social constructs" as "...few features of language directly and exclusively index gender" (1992: 340). She also notes that referential indexes of social meaning such as pronouns, titles and honorifics are not nearly as common as nonreferential indexes. The events discussed below will not deal with as complex a social category as gender but will focus on the relation of language to oppositional stances and social acts developed by members of opposing groups.

As Ochs' 1992 model suggests by having the lexicon at the top of the bracketed list of linguistic resources, (see Figure 14.2), the referential indexes for the oppositional groups are essential in the construction of these dispute events. ${ }^{8}$ When group membership and the ensuing ideological differences are the topic of dispute, the very act of "assigning participants to membership categories," contrary to Jacoby and Ochs' dismissal (1995: 177), begins the creation of the oppositional selves.

Adams and Winter (1997), for example, show that in gang graffiti every one of the recorded surfaces is specified with a gang name. Gang names are the most frequently occurring utterances in our data, and a minimal conflictive interaction consists of two gang names, the first crossed out by the writers of the second. The mere writing of a gang name asserting the presence of a member and his gang initiates the dispute exchange if a rival gang sees the graffiti and is free to respond. An individual gang member's name or any of the other disrespectful utterances or threats are typically meaningless without the gang name identifying who is backing up the threat. When compared to non-disputed graffiti, the disputed turns have gang names written more frequently, thus demonstrating the importance of specifying the group when creating conflict. Its increased repetition within

\footnotetext{
${ }^{7}$ The idea for the work on gang graffiti started as a research paper for Adams' Pragmatics and Discourse Analysis course, August-December, 1994. Winter collected data and interviews from November 1993 through May 1995 and presented the initial analysis. Upon further discussion, collaboration seemed a fruitful approach. Additional data including interviews with a questionnaire were jointly collected and all the data were analyzed June through December 1995.

${ }^{8}$ As one reviewer noted this claim does not mean to ignore the possibility that the lexicon can also be an 'indirect' index.
} 
a turn clarifies what the conflict is over-opposing gang membership and claims of superiority.

Linguistic resources:

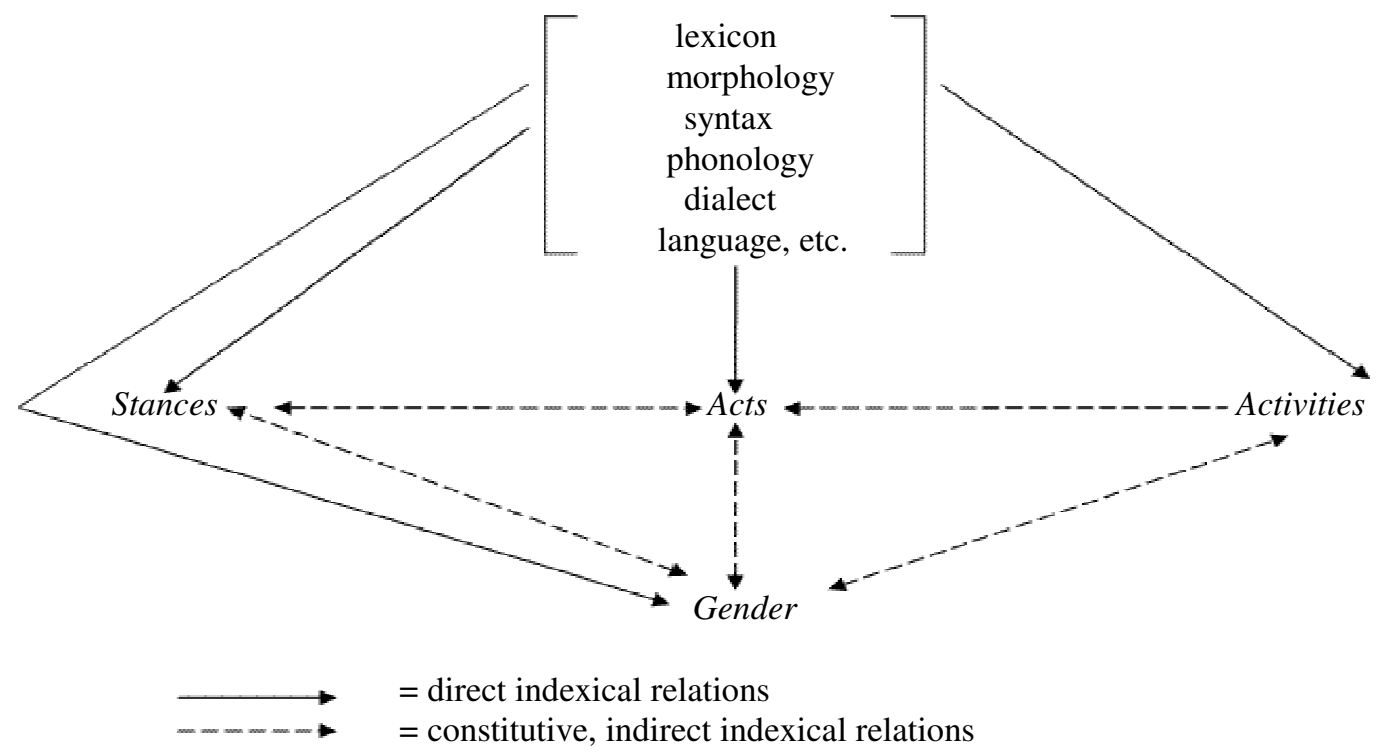

Figure 14.2 Language and gender

(from Ochs 1992: 342)

The writers of gang graffiti, as with the participants in the other events discussed here, are multiply voiced. When an individual member writes, he (or she) may minimally write the gang name or he (or she) may choose to uniquely identify himself by writing his gang nickname as well as those of other members who might be present. He may also have a distinctive writing style that identifies him as the writer or 'principal' of the utterance in Goffman's terms (1972). However, he is also always seen as talking for the gang. Former gang members reported to Adams and Winter cases where hostilities between gangs were forced upon some members by another part of the gang, often younger and more aggressive members, writing threats and boasts. Once written, all gang members were seen as principals or originators.

As with gang graffiti, the identification of a candidate's party membership is also critical in the political debates. At the time a candidate is introduced in the debate, the party affiliation is typically specified in the following fashion:

(1) Announcer: Live from the Devaney Sports Center on the University of Nebraska Lincoln campus, this is the debate for governor between Democratic challenger Ben Nelson and incumbent Republican Kay Orr, sponsored by the Nebraska Press Association. (Nebraska 1990: 1)

Out of 57 debates where candidates from more than one party were running, 81\% (46/57) of them had the candidates' party affiliation specified by the moderator's introduction typically within the same phrase or within one or two phrases after their name was given. 
Following appositives, embedded $w h$-clauses or attributive adjectives are used to indicate party affiliation.

In the debate event, one might assume that much of the viewing audience already knows a candidate's affiliation, especially that of the incumbent given the U.S.A.'s basically two party system. But by specifying the party close to the candidate's name, the listener recognizes and anticipates the potential conflict since the political system demands a 'fight' where one party must vanquish the other as well as adhere to ideological principles associated with the party.

Of the eleven debates where the party was not immediately specified, three were second debates and the opposing party membership had been televised earlier. Several others of these eleven debates had opening statements by candidates or introductions by announcers that indicated party identity through relationship to another candidate who was running for a different office or through opposition to a candidate currently in office. Interestingly, in three of the four debates from the state of Louisiana, candidates' party affiliation was not specified in the moderators' statements, but twice candidates took it upon themselves at strategic opening or closing statements to make sure their party identity was given. The lack of party identification can be considered problematic for candidates as it obscures their allegiances to the viewing public. As with the gang graffiti, candidates for office are multivoiced, not only representing themselves, but also the party supporting them, and, if they currently hold or have held office, the government, the people who voted for them, and their general constituency.

The 1984 Arizona gubernatorial race demonstrates this potential need to clarify voices. In that race, the Republican candidate Evan Mecham, rather than allowing one of the other candidates claim identity as an independent chose to 'out' him in his opening statement with, "I'm running against two Democrats who differ greatly from me on many issues." (Arizona 1984: 4).

The news commentary show "To The Contrary" demonstrates a different pattern of membership categorization perhaps because the consequences of prevailing are less and hence so is the participant's role in creating conflict. Opposition here is over specific issues that are presented for discussion; but while a panelist speaks to convince the audience, providing information and entertaining them are also goals, not winning an election or a fight. And though the panelists from differing political sides, ethnic groups and age groups deconstruct notions of a single female perspective, there are occasional segments on the show, usually at the end, where responses to issues anticipate agreement among them.

Panelists on the show are identified initially by personal name only. Only after the opening topic in which the participants are required to set themselves up with regard to a political stance is additional information about occupation and affiliation mentioned. The commentators in the two shows in question are identified as from the Heritage Foundation, the Manhattan Institute, and the Diario Las Americas or as a political commentator, a syndicated columnist, and a former labor secretary-identities that without prior knowledge of the organizations, the publications or the speaker and without reliable memories about political administrations do not allow ranking on a left to right spectrum.

During the half-hour program, panelists do on occasion identify themselves or are identified by other panelists as a political group member through first and second person anaphoric reference. For example, in the following exchange, Kate O'Beirne, from the Heritage Foundation, criticizes liberals. Erbe, the moderator, interrupts with a joke and 
Julianne Malveaux, a syndicated columnist, responds identifying herself as liberal.

(2) ("To The Contrary"-1993a: 7) (underlining added)

O'Beirne: ... the liberals blamed Ronald Reagan and George Bush for everything---homelessness, child abuse, drug abuse, pollution... (exaggerated intonation mocking an endless list, broad head gestures)

Erbe: Traffic jams. You forgot traffic jams.

Malveaux: Oh no, we didn't blame them for that.

Such identifications may also include other relevant categories for ideological positions such as ethnic identity.

However, these identifications are not common. In "To The Contrary," it is the political position taken on issues that co-constructs the oppositional roles as commentators. These positions may be very similar to those taken by a candidate for office in the debates, but the panelists are not hoping to win an election so party/political identity is not at the forefront, oppositional issues are. The oppositional ideologies are constructed at the very beginning of the show directly after the introduction of the hosts and panelists. As we can see from the following examples, the initial utterance of the moderator determines the topic in newspaper headline fashion. Then the panelists are asked a Yes/No question to elicit their positions on the nature of the new Democratic administration under Clinton. In (3) the controversy is over Clinton's stance on the place of homosexuals in the U.S. military. After election, when the U.S. Congress challenged him, Clinton backed away from his campaign position supporting homosexuals' rights.

(3) ("To The Contrary" 1993b: 1)

Erbe: President Clinton delays lifting the ban against homosexuals in the military. Has he lost face in his first major political battle with Congress?

By orienting oneself positively, neutrally or negatively towards the people and issues in these introductory questions, as well as by selecting issues to comment on, the panelists begin creation of oppositional identities. This creation can be seen in (4) where they alternate pro and con while answering Erbe's question.

(4) ("To The Contrary" 1993b: 1)

Martin: Running the Arkansas National Guard wasn't enough experience for this President. It's a shuffle.

Natividad: Clinton's lost no political capital. This president is popular and people's memories are short.

Chavez: He may finally have come to his senses, and if he hasn't, congress surely will.

Malveaux: Bill blinked, but Congress will have to fold. This is a human rights issue.

In (4) Martin defines Clinton as inexperienced and waffling, indicating that his experience with armed forces as the Arkansas governor was inadequate. Chavez criticizes the stand he took during the campaign also showing herself to be critical of Clinton or of the typical 
Democratic stand on the rights of homosexuals. Natividad, on the other hand, claims he has lost nothing, and Malveaux takes the liberal stand on this issue, thus supporting the rights of homosexuals.

\subsubsection{Tense and person choices in representing ideology}

As interesting as the political stances themselves, are the ways in which they are structured. A comparison of the responses in the two programs in question shows that panelists frequently introduce their initial opposing ideological positions in single independent clauses with the use of predicate adjectives or nominals pushing to the foreground the evaluative markers. These strategies can be seen in the second sentences in Martin's, Natividad's and Malveaux's responses in (4). Tense/aspect choice also frames their immediacy of effect as does Natividad's decision to mark the negative on the noun phrase rather than saying "Clinton hasn't lost any political capital."

The use of these strategies and the fact that the arguments are presented in the third person with no hedging means that these statements are clearly in opposition to each other. The same effect was created in the opening a week earlier where each panelist took different positions speaking as though she were representing all women. For example, in that exchange, panelist Kate O'Beirne says, "American women are watchful.", while Anne Lewis says, "Women's lives are better already." ("To The Contrary" 1993a: 1). Fairclough (1992: 159) argues that the use of objective and categorical modality expressed through third-person present-tense statements "...often implies some form of power." What we see happening in these expressions of ideological opposition are the use of forms that create powerful and exclusive stands denying the truth of the other.

The identification of ideological positions is also the mainstay of televised debates, though one long-term criticism of these debates is that the opposition in debates is created between the panelists and the candidates, not between the candidates. Moreover, candidates are often chided for negative campaigning and may take care in the kind of opposition they express. But as with "To The Contrary", the floor is typically structured to allow for the expression of opposing ideological notions, especially through the opportunity to make opening and closing statements. Of the 57 debates discussed here, $91 \%$ of them $(52 / 57)$ have opening or closing sections or both. Of the five that do not, two were exclusively a call-in format and two others were only 10 minute debates where the candidates were not even in the same studio. The importance of these sections can be seen in the fact that these are where candidates can create a whole positive persona for themselves, criticize opponents' stands and make clear a more complete ideological position.

As Brenneis and Lein (1977) point out, an important part of antagonistic exchanges are claims, the support of claims and challenges to them. As we have seen above, in the "To The Contrary" examples, expressing the claims with certain grammatical structures including modal and person choices can intensify their nature. Other effective counterclaims in "To The Contrary" also may rely on claiming group identity as an unchallengeable voice. For example in the January 21st show, Julianne Malveaux responds to the following statement from Kate O'Beirne. 
(5) ("To The Contrary" 1993a: 5) (underlining added)

O'Beirne: Republicans are nicer people, Bonnie. [That's

Malveaux: [Not.

O'Beirne: =perfectly clear. [The

Malveaux: [Not.

O'Beirne: = whole issue ... the Republicans for the past twelve years have felt so uncomfortable with the politicization of the confirmation process where the trivial is made mammoth because of political differences. ...I think they [the Senate] are increasingly finding out that this is the kind of thing families talk abut over the kitchen table, Zoe Baird's employing those illegal aliens, and they're maybe hearing ... that this one may be important for a future attorney general.

Erbe: Was the specter of Anita Hill hanging over these hearings, Juli[anne? Malveaux: [Absolutely. Seventy percent of all black women worked as domestics in 1940. Carol Braun raised the question of the Peruvian women because we don't find people, Kate, trivial nor do we use the word alien to describe human beings.

Here Malveaux challenges a claim about niceness immediately, but it is her stinging response to the characterization of issues dealing with lower class working women of color that is so devastating. Malveaux is a Black woman, but she chooses only to foreground this here and in one other case in this broadcast. She leaves O'Beirne responseless and appearing chagrined as the camera focuses in on her facial response to this remark. (The omission of women of color from feminist agendas has long been a topic of controversy for feminists and those concerned with women's issues.) A week later she also employed her identity to criticize Linda Chavez in the following exchange.

(6) ("To The Contrary" 1993b: 10) (underlining added)

Malveaux: There's always been self-help in the African-American community. If we waited for government, we'd get nothing. Linda's absolutely wrong to talk about Jacob's call as disgraceful.

\subsection{Directed and unmitigated stances}

Examples (5) and (6) demonstrate another strategy in the co-construction of opposition. Direct address and reference to other participants' arguments intensifies the opposition because it foregrounds and pinpoints with whom the disagreement is.

The use of direct address among the panelists in "To The Contrary" is rare, as it is between candidates in the debates, since most exchange is directed through the moderator or in the debates through the panelists who ask the questions. ${ }^{9}$ In "To The Contrary"

\footnotetext{
${ }^{9}$ In some debates, candidates are not even asked questions on the same topic. Also when candidates are given the opportunity to question each other directly, some candidates refuse to do so or turn their question into a joke. I believe this to be an extension of this concern of directing challenges and looking 'too hostile' to the audience.
} 
episodes, it is also rare to directly attribute an argument to one of the other panelists. Table 1 ( $a$ and $b$ ) demonstrates a clear difference in the use of this strategy among the panelists with Julianne Malveaux consistently a high user of this strategy. As I argue elsewhere (Adams 1999), Malveaux is one of the most successful practioners of the "To The Contrary" style including direct address. What is most interesting about the use of these forms in these events is that they occur during acts of disagreement, only Chavez uses them once to support another panelist. ${ }^{10}$

TABLE 1a: DIRECT ADDRESS AND ATTRIBUTION: 1/21/93

$\begin{array}{lll}\text { Address } & \text { Named } & \text { Total } \\ \text { by Name } & \text { Attribution } & \end{array}$

$\begin{array}{rllll}\text { Ferre } & 0 & 0 & 0 & 00.0 \% \\ \text { Lewis } & 3 & 1 & 4 & 25 \% \\ \text { Malveaux } & 5 & 1 & 6 & 37.5 \% \\ \text { O'Beirne } & 4 & 2 & 6 & 37.5 \%\end{array}$

TABLE 1b: DIRECT ADDRESS AND ATTRIBUTION: 1/28/93

$\begin{array}{lll}\text { Address } & \text { Named } & \text { Total } \\ \text { by Name } & \text { Attribution } & \end{array}$

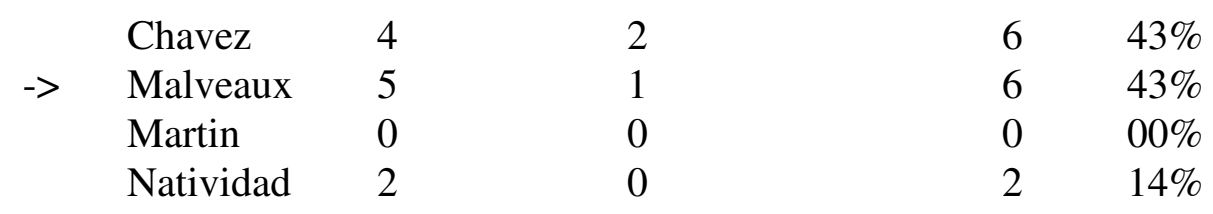

In the openings and closings of televised debates, the most common strategy for the use of names, as with the other events, is not to directly name your opponent. In fact, candidates may be encouraged not to name their opponents thus cutting down on name recognition and avoiding the appearance of attacking the opponent too much. In $62.2 \%$ $(122 / 196)$ of the openings and closings, one candidate did not directly name her/his challenger.In another $12.7 \%$ of these turns, some kind of alternative label was used such as opponent, or there was criticism of a running mate or of liberal or conservative viewpoints. When an opponent's name did appear in openings and closings, it was typically in an environment criticizing them, also intensifying the counterclaim.

Another strategy that shows up in example (5) is Malveaux's one word negative response in the middle of O'Beirne's answer. These immediate one word, one phrase interjections and answers to questions intensify the stance of the panelist. When Lewis, Malveaux, O'Beirne and Chavez begin answers with Absolutely., Absolutely right., Exactly right., Not at all., Slow., or interject Not., one can again see forms constructing unmitigated opposition. These unmitigated utterances are like the single word utterances of the gang graffiti where murder is threatened by the expression 187 or mourning for a dead gang

\footnotetext{
${ }^{10}$ The moderator, of course, also uses direct address to nominate speakers, and they may respond in kind.
} 
member with only RIP. ${ }^{11}$ These expressions leave no doubt as to the opposition or support with regards to the other speaker/writer.

As with the media events, gang graffiti also uses claims and counterclaims. Mostly these counterclaims are done merely by crossing out the other gang's name and hence its presence with all that may mean. But a small percentage of the graffiti in Phoenix also includes threats, challenges, boasts. Threats might include abbreviations such as $B K$ standing for 'Blood killer' meaning that the members of the one gang, perhaps a 'Crip' gang, kill members of 'Blood' gangs. They might write solo \#1, 'alone \# one," meaning they are the top gang. These threats and challenges are also made more intense with the inclusion of a gang member's name either as the one who will carry out the threat or as the one threatened. ${ }^{12}$

Other strategies for intensifying opposition in gang graffiti include the visual manipulation of the writing. Writing larger or repeating the gang's name or threat may function in this manner just as in spoken interactions, the person's volume may increase or their look may intensify. Such strategies parallel the use of adjectives more strongly marked for positive or negative feelings and beliefs in the televised events. When looking at the expression of the panelists' own emotional states in the January 21st broadcast, Malveaux again strengthens her stance by claiming to be frightened and horrified while other panelists use the milder concerned.

\subsection{Floor control}

As important as lexical, grammatical and prosodic/graphic strategies are issues of floor apportionment, a category allowed for in the 'etc.' in Ochs 1992 Figure 14.2. In both the political debates and the commentary shows the allocation of floor space is typically agreed upon to some degree prior to airing. The opportunity to open discussions, to have more floor space and to have the final say can mark the status of the speakers and also influence the perception of successfully creating an opposing stance.

Certainly in gang graffiti, position of utterance and floor space matter in the perception of success. The last remaining uncrossed out utterance in graffiti is equivalent to the boxer who remains standing. Gang members feel the necessity to respond to the utterance of opposing gang members particularly if it is anywhere close to their residence or hangouts or if the message is particularly hostile. Wall/floor space can also become important in that the number of times a gang name appears and the amount of space the

\footnotetext{
${ }^{11}$ There are many reasons for gang members to keep their messages brief. They are meant to be cryptic and not easily understood by people outside the gang culture. Also writing is illegal in Arizona as well as potentially deadly if an opposing gang finds you writing disrespectful messages; consequently, writing-time is limited. Paint is also expensive and not always easy to get as many stores keep it locked behind the counter.

${ }^{12}$ The seriousness with which threats are taken in gang writing depends on several circumstances, whether it is personally directed or signed and where it is written - for example, right on or adjacent to the house of the person being threatened or on a major thoroughfare. Gang names written on a major thoroughfare where members of other gangs may only occasionally pass by might not require an immediate writing over.
} 
gang name covers increases in our data the likelihood of a response that escalates the dispute.

Interrupting another gang member's turn also plays an important role in successful hostility in this context. For example, inverting a rival gang member's utterance by changing the $C$ in $C K$ 'Crip Killer' to a $B$ for 'Blood Killer' according to our consultants is seen as very successful, creating annoyance and anger in the first writer as the killing now refers to his own gang. Here co-constructing conflict by turning a rival's utterance against him is particularly effective.

The importance of floor apportionment in deliberate dispute events can also be seen in the structure of televised political debates which seek to control this very factor. As discussed in Adams 1992 the preallocation of turn order, turn topic and floor space is divided among the candidates in a way meant to be seen as equal and unbiased. Who starts or finishes is decided by a toss of the coin, so luck determines the ability to talk first and last rather than the status of elected office, or position in the polls or party status. The goal in debates is also to allocate all candidates the same amount of time to talk, though as noted in Adams 1995, there is some bias in the way floor space is handled by moderators.

While candidates and moderators recognize the benefits that an equally divided floor has in overcoming contextual inequalities, they do, though, choose to violate their turn allocation and take turns that have not been given to them. Adams 1992 shows that the likelihood that these are for contentious reasons vary to some degree for the female and male candidates in question, but most uninvited turns in the data discussed there were contentious, $59 \%$ in total. ${ }^{13}$ The very requirement that these issues be controlled in the televised debates shows that in co-constructing conflict we can expect floor apportionment to be part of winning and losing and a strategy over which different speakers have different access and beliefs. A candidate violating the predetermined rules about the floor can increase the perception of involvement and competitiveness but also risks being perceived as not playing by the rules if taken to an extreme. ${ }^{14}$

In "To The Contrary," one would expect floor space and turn position to be approximately similar for all participants if views are to be represented equally as they are in the televised debates. The following table ( $2 a$ and $b$ ) shows the distribution of several of these features among the panelists in the two broadcasts. What is striking here is that if one looks at Julianne Malveaux's share of the floor both in terms of words spoken and in terms of opportunities to open and close, she typically dominates, especially in getting the last word. This dominance suggests that the producers who have general control over the floor also perceive her as more successful than others in providing the right oppositional tone, particularly in closing.

${ }^{13}$ In the debates, the lowest number of contentious uninvited turns were $44 \%$ for women in mixed sex debates and the highest number were $78 \%$ for men in mixed sex debates. Agha (1997) also notes the use of such violations for building opposition in the Clinton/Dole debate.

${ }^{14}$ The perceived overuse of such violations as in the Ferraro, Holtzman, Sharpton and Abrams New York Democratic Primary Senate race in 1992 can lead to negative responses by voters. 
TABLE 2a. FLOOR APPORTIONMENT: 1/21/93

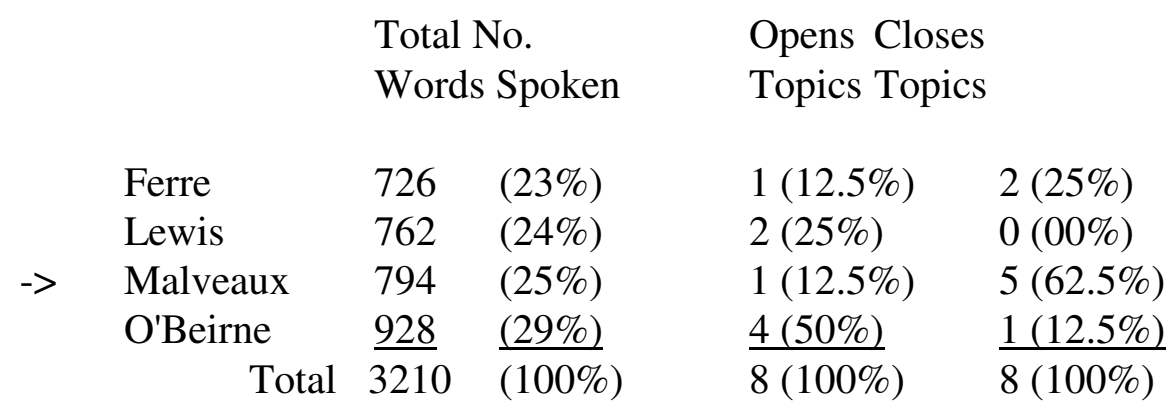

TABLE 2b. FLOOR APPORTIONMENT: 1/28/93

\begin{tabular}{|c|c|c|c|}
\hline \multirow[b]{2}{*}{ Chavez } & $\begin{array}{l}\text { Total No. } \\
\text { Words Spoken }\end{array}$ & \multicolumn{2}{|c|}{$\begin{array}{l}\text { Opens Closes } \\
\text { Topics Topics }\end{array}$} \\
\hline & $(25 \%)$ & $1(20 \%)$ & $0(00 \%)$ \\
\hline Malveaux & $(28 \%)$ & $1(20 \%)$ & $5(100 \%)$ \\
\hline Martin & $(28 \%)$ & $2(40 \%)$ & $0(00 \%)$ \\
\hline Natividad & $(18 \%)$ & $1(20 \%)$ & $0(00 \%)$ \\
\hline Total & $(100 \%)$ & $5(100 \%)$ & $5(100 \%)$ \\
\hline
\end{tabular}

As with the debates and graffiti, the invasion of another's turn space is a marker of increasing hostility. Others' floor space may be interrupted or overlapped for several reasons, but antagonism is clearly one of them. When comparing the moderator and the panelists on "To The Contrary," the function of their overlapping and interrupting speech clearly marks their roles. The pace of exchange is quick in this program and overlapping is not uncommon. For example, in the first broadcast on January $21 \mathrm{st}$, Erbe, the moderator, overlaps speech and takes over the floor five times to nominate another speaker, change the topic, clarify the direction of the topic and once to make a joke, in other words, to moderate the activities of the panelists. ${ }^{15}$ Twice, however, she comes in at a non-turn-relevance-point to disagree with one of the panelists on the topic of media bias when a group she represents is being attacked. For the panelists, interruptions and overlapping speech are almost exclusively for disagreeing even though each panelist has what could be construed as one other ally on the floor. In the January 21 st show, for instance, all of the overlaps and interruptions by panelists are to disagree, and in keeping with the earlier claim that Malveaux is one of the best practitioners of oppositional style, she moves in on others' turns the most frequently.

\footnotetext{
${ }^{15}$ The panelists on occasion overlap her at the start of their turns after their nomination. Given the time-driven nature of the exchanges this is not surprising.
} 


\section{The implications of breaking frames}

As Jacoby and Ochs (1995) argue, the strategies used here are not ones that are completely predetermined, and in each of the events discussed, we find a few cases where the participants choose not to invoke established patterns. But what is of interest in these cases is how such disruptions serve to carry messages that challenge the dispute event and the ideology behind it or serve to force participants into reestablishing the dispute pattern.

Adams and Winter (forthcoming) note one example of gang graffiti where the writers move away from the use of abbreviations and hostile utterances to make a plea for peace. This statement is introduced by a typical gang greeting and followed by typical rest in peace lists of members who have been killed. But in between is written the following message, "We are not against you esse! Your friends. homes" (Cardona 1993). (Esse is a greeting/direct address to Hispanic gangs and Homes here refers to 'Happy Homes,' a name of one of the gangs.) This is the only utterance in our data that contains a complete sentence. Moreover, the use of we and your is rare in these data and never in the same expression, and this is the only instance of the use of the term friends. As we argued earlier, the introductory and concluding formulaic writing defines the message as authentic; the broken frame as a genuine and heartfelt plea.

The alternative use of strategies in "To The Contrary" occurred in the January 21st broadcast, where one panelist, Helen Ferre, repeatedly constructed her utterances using different strategies. (The use of these alternative strategies is discussed fully in Adams (1999).) Her style can create an initial perception of Ferre as less successful than the other three participants in co-constructing an oppositional persona, and the fact that Ferre was not a frequent participant on the show may explain her having less familiarity with the expected format. But Ferre's own comments during a discussion of bias in the news media indicate another reason for her discomfort with the confrontational stances of the other panelists. She states at one point that a news story should be "... justified, and everything ... well-presented, ... balanced" ("To The Contrary" 1993a: 12). Later she states, "I'm concerned that the media tends to be too confrontational." ("To The Contrary" 1993a: 15). Her breaking the "To The Contrary" style reflects these attitudes.

In a last example of frame breaking, rather than trying to limit hostile linguistic stances as Happy Homes and Helen Ferre did, all but one of the candidates in a Louisiana primary for governor attempted to reestablish the frame after it had been broken. This debate includes 10 candidates from both the Democratic and Republican parties and is one of the few debates where the moderator did not identify candidates by party at the beginning as at that time Louisiana had primaries open to anyone regardless of party. The questions asked by the panelists were not necessarily designed to reveal affiliation either. Given this perceived failure, the candidates took it upon themselves in their closing statements to identify their party affiliation and hence their allegiances and overall ideological positions to the audience. Only one candidate tried to continue to avoid this identification as she wanted to appeal to voters in both parties. She did that by claiming, "This election is not about labels or really about political parties." (Louisiana 1996: 42). But just as in the earlier example with Evan Mecham in Arizona, other candidates outed her by saying such things as "On the other end, you have a very liberal Democrat, who is clothed in conservative rhetoric." (Louisiana 1996: 45).

These examples of breaking frame and correcting broken frames serve to 
demonstrate the anticipated norms of deliberate dispute as they create their different viewpoint only by being able to work against the accepted strategies of creating oppositional stances in these activities.

\section{Conclusion}

While every event under consideration here has unique ways in which participants jointly construct these events, it is inappropriate to ignore the Bakhtinian notion that texts are "the products of previous, current, future and hypothetical dialogues with other interlocutors" (Jacoby and Ochs (1995: 173). Though Jacoby and Ochs (1995: 177) claim that "such allegedly 'stable' things as ... rules of a game, classifications of interactional events, ... are highly contingent and constantly shifting, as interlocutors co-construct interactional moments," the regularities found in such a large number of deliberate dispute events clearly demonstrate intertextuality and argue against the assumption that such events can be constructed anew every time. As Potter and Wetherell state (1987: 103-04)

"... there is considerable constraint and regularity in the procedures people use for articulating or making sense of an action, and successfully 'bringing off' their version of events in a persuasive manner. We would want to argue that not every interpretation or construction of the self will be acceptable in a specific situation."

Intertextuality is a complex concept in that a current text can be related to many different prior, future and hypothetical texts. Moreover, there are many different linguistic strategies revealing intertextuality. These can range from the obvious one of directly quoting from another particular identified text to the kind of complex relationships existing in the cases here. While the individual texts in question may have examples where one text is clearly cited in another, what is of concern is more what Fairclough (1992: 121) refers to as "accumulated textual experience," or genres associated with participants in activity types. For example, the discourse of campaigning in the United States has associated with it many activities including formal televised debate.

A theory of indexicality presents a model for citing the elements characteristic of specific deliberate dispute genres and the culturally anticipated ways of creating oppositional stances in these genres. The elements used to create these stances are obviously separable in that they reoccur in different genres, and they can also be combined with other strategies to create the genres which are uniquely associated to the activity types.

In deliberate disputes, initializing the events with the opposing groups' identities and/or with their opposing ideological positions is crucial. This sets the frame as a whole for what the event is about and what can be expected from the participants. Moreover, presenting ideological positions with third-person present-tense utterances or with claims of unique group membership and knowledge assert unassailable opinions and metaphorically erase the opposition's position. The speech acts of disagreements, threats, counterclaims can also be intensified by directed address and reference and by increases in graphic size or oral volume and the use of unmitigated expressions of agreement and disagreement. While, for example, direct address is a strategy common in many texts, it is strongly associated here with statement of disagreement by opponents. Floor apportionment is also critical in these contexts, and opposing participants typically assume that the more 
one group controls the floor the more likely their ascendancy.

These elements of stance (related to 'rhetorical mode' in Fairclough (1992: 127)) are intertextual both within and across genres. Other examples of possible deliberate dispute clarify the notion that indexing stance is a separable event from the activity in question. For example, during team sporting events, fans yell back and forth the names of teams or universities also initializing what the struggle on the athletic and the audience floor is over (7).
a) A-S-U
b) U-of-A

In addition, opposing fans may also operate to 'cross out' the other team's identity or their credibility in a chant such as the following.
a) A-S-U
b) Who?

The potential for creativity in the co-construction of disputes must be understood in terms of altering the elements of these stances. Participants including audience recognize the challenge because of intertextual knowledge. The creation of new meanings of self or their rejection are an inherent part of prior, future and hypothetical texts. These 'shifting rules' and 'selves' may or may not succeed in altering these other texts.

This analysis also suggests some modifications in the model presented by Ochs in Figure 14.2 (1992: 342). The list of linguistic resources, for example, is incomplete. The dynamics of deliberate dispute show clearly the importance of interaction and issues of floor apportionment as a resource. Questions remain as to how finely resources should be specified in the theory, and if the resources might be ordered in some fashion in terms of importance for the construction of different identities, stances and activities, and how indirect indexical relations are interpreted. In the events here, for example, direct reference to the oppositional roles and ideologies is crucial in initializing the expectation of oppositional stances. We need to pursue the answers to these questions in further work with the theory looking at other kinds of stances, their relationship to specific activity types, and their degree of intertextuality.

\section{References}

Adams, Karen L. (1992) Accruing power on debate floors. In K. Hall, M. Bucholtz \& B. Moonwomon (eds.), Locating power: Proceedings of the second Berkeley women and language conference. Berkeley: Berkeley Women and Language Group, University of California, pp. 1-10.

Adams, Karen L. (1995) "Time's up." and "It's not your turn.": Enforcing and obeying limits in televised political debates. Paper presented at the conference on Political Linguistics, Antwerp, December 7-9.

Adams, Karen L. (1999) Creating 'to the contrary' selves for the television audience. Language Sciences 21: 303-311. (Special issue, N. Love, (ed.) C. Basham, S. Fiskdal \& P. Rounds (guest eds.), The notion of person.)

Adams, Karen L. and Anne Winter (1997) Gang graffiti as a discourse genre. Journal of Sociolinguistics 1.3: 337-359. 
Adams, Karen L. and Anne Winter (forthcoming) Group and individual identity in gang graffiti. In S. Coffey, S. Graham \& R. Hoopes (eds.), Discourse as mosaic: Linguistic re/production of identities \& ideologies. Georgetown University.

Agha, Asif (1997) Tropic aggression in the Clinton-Dole presidential debate. Pragmatics 7.4: 461-497. (Special issue, C. Briggs (ed.), Conflict and violence in pragmatic research.)

Arizona (1984) Gubernatorial Debate (1984) Transcript.

Blume, R. (1985) Graffiti. In T. van Dijk (ed.), Discourse and literature. Amsterdam: John Benjamins, pp. 137-148.

Brenneis, Donald (1988) Language and disputing. Annual Review of Anthropology 17: 221-217.

Brenneis, Donald and Laura Lien (1977) "You fruithead:" A sociolinguistic approach to children's disputes. In S. Ervin-Tripp \& C. Mitchell-Kernan (eds.), Child discourse. New York: Academic Press, pp. 49-65.

Briggs, Charles (ed.) (1997a) Conflict and violence in pragmatic research. Pragmatics 7.4 (Special Issue).

Briggs, Charles (1997b) Introduction: From the ideal, the ordinary and the orderly to conflict and violence in pragmatic research. Pragmatics 7.4: 451-460. (Special issue, C. Briggs (ed.), Conflict and violence in pragmatic research.)

Cardona, Samuel Don (1993) Photographs. Chicano Research Collection, Hayden Library, Arizona State University, Tempe, AZ. MP SPC 287.1-188.

Fairclough, Norman (1992) Discourse and social change. Cambridge, UK: Polity Press.

Goffman, Erving (1974) Frame analysis. New York: Harper and Row.

Goodwin, Marjorie Harness (1990) He-Said-She-Said. Bloomington: Indiana University Press.

Grimshaw, Allen D. (ed.) (1990) Introduction. In Conflict Talk. Cambridge: Cambridge University Press, pp. 1-20.

Haviland, John B. (1997) Shouts, shrieks, and shots: Unruly political conversations in indigenous Chiapas. In C. Briggs (ed.), Conflict and violence in pragmatic research. Pragmatics 7.4: 547-573. (Special Issue)

Jacoby, Sally and Elinor Ochs (1995) Co-construction: An introduction. Research on Language and Social Interaction 28.3: 171-183. (Special Issue: Co-construction.)

Levinson, Stephen C. (1992) Activity types and language. In P. Drew and J. Heritage (eds.), Talk at Work. (Studies in Interactional Sociolinguistics 8). Cambridge, UK: Cambridge University Press, pp. 66-100.

Louisiana (1996) Primary Senate Debate. (1996) Transcript.

Nebraska (1990) Gubernatorial Debate. (1990) Transcript.

Ochs, Elinor (1990) Indexicality and socialization. In G. Herdt, R. Shweder, and J. Stigler (eds.), Cultural psychology: Essays on human development. Cambridge: Cambridge University Press, pp. 287-308.

Ochs, Elinor (1992) Indexing gender. In A. Duranti and C. Goodwin, (eds.), Rethinking context: Language as an interactive phenomenon. Cambridge: Cambridge University Press, pp. 335-358.

Potter, Jonathan and Margaret Wetherell (1987) Discourse and social psychology: Beyond attitudes and behaviour. London: Sage Publications. 


\section{Karen L. Adams}

Silverstein, Michael (1985) Language and the culture of gender: At the intersection of structure, usage and ideology. In E. Mertz, and R. Palmentiers (eds.), Semiotic Mediation, pp. 219-259.

Tannen, Deborah (1998) The Argument Culture: Moving from Debate to Dialogue. New York: Random House.

"To The Contrary." (1993a) January 21, 1993 Transcript, \#143. Owings Mills, MD.: Maryland Public Television.

"To The Contrary." (1993b) January 28, 1993 Transcript, \#144. Owings Mills, MD.: Maryland Public Television.

"To The Contrary." (1998) October 17, http://www.pbs.org./ttc/. 